\title{
Fluid Filtration and Rheological Properties of Nanoparticle Additive and Intercalated Clay Hybrid Bentonite Drilling Fluids
}

\author{
Matthew M. Barry ${ }^{1}$, Youngsoo Jung ${ }^{1}$, Jung-Kun Lee ${ }^{1}$, Tran X. Phuoc ${ }^{1,2}$, \\ Minking K. Chyu ${ }^{1 *}$ \\ ${ }^{1}$ Department of Mechanical Engineering and Materials Science, \\ University of Pittsburgh, Pittsburgh, PA 15261, USA \\ ${ }^{2}$ National Energy Technology Laboratory, U.S. Department of Energy, Pittsburgh, PA \\ 15236, USA
}

\section{Abstract}

The fluid filtration and rheological properties of low solid content (LSC) bentonite fluids containing iron-oxide $\left(\mathrm{Fe}_{2} \mathrm{O}_{3}\right)$ nanoparticle (NP) additives and two different NP intercalated clay hybrids, iron-oxide clay hybrid (ICH) and aluminosilicate clay hybrid $(\mathrm{ASCH})$, under both low-temperature lowpressure (LTLP: $25^{\circ} \mathrm{C}, 6.9$ bar) and high-temperature high-pressure (HTHP: $200{ }^{\circ} \mathrm{C}, 70$ bar) conditions are investigated. The viscosity of each fluid was measured under LTLP and HTHP conditions using a pressurized and heated rotational viscometer. The LTLP and HTHP fluid filtrate volumes were measured in accordance to American Petroleum Institute standards. The addition of $\mathrm{ICH}$ and $\mathrm{ASCH}$ into bentonite solutions reduced both LTLP

\footnotetext{
*Leighton Orr Chair Professor and Chairman and Corresponding author, Ph: 412-6249720 Fax: 412-624-4846

Email addresses: mmb49@pitt.edu (Matthew M. Barry ${ }^{1}$ ), yoj14@pitt.edu (Youngsoo Jung ${ }^{1}$ ), jul37@pitt.edu (Jung-Kun Lee ${ }^{1}$ ), Phuoc.Tran@netl.doe.gov (Tran X. Phuoc ${ }^{1,2}$ ), mkchyu@pitt.edu (Minking K. Chyu ${ }^{1}$ )
}

Preprint submitted to Journal of Petroleum Science and Engineering October 28, 2014 
and HTHP fluid loss as much as $37 \%$ and $47 \%$ as compared to the control, under the respective conditions. The pure addition of $0.5 \mathrm{wt} . \% 3$ and $30 \mathrm{~nm}$ $\mathrm{Fe}_{2} \mathrm{O}_{3}$ NP increased the LTLP fluid filtration as much as $14 \%$ as compared to the control. However, this addition of $\mathrm{Fe}_{2} \mathrm{O}_{3} \mathrm{NP}$ decreased the HTHP fluid filtrate volumes as much as $28 \%$ as compared to the control. It was found the addition of clay hybrids reduced LTLP and HTHP fluid loss due to a restructured mode of clay platelet interaction attributed to a modification in surface charge as demonstrated by zeta potential measurements and scanning electron microscope images.

Keywords: Bentonite solution, drilling fluid, filtration, high-temperature high-pressure, nanoparticle embedded clay hybrids, iron-oxide, low-temperature low-pressure, rheological behavior

\section{Introduction}

1

Bentonite is a montomorillonite (Mt) clay commonly used in conventional water-based drilling fluids due to inherent, well-performing rheological properties and the vast knowledge thereof $[1,2]$. Mt clay solutions exhibit shearthinning viscosities which provide good pumpability and carrying capacity of cuttings [2]. Additionally, Mt clay forms relatively low permeability filter cakes on the borehole surfaces [3]; thick filter cake formations reduce the effective diameter of the borehole, which causes excessive drag, torque losses, high swab and surge pressures and increases the risk of differential sticking of the drill string [4]. Mt clay begins to chemically break down at temperatures as low as $120^{\circ} \mathrm{C}$ [5], increasing the drilling fluid loss into sub-surface formations and reducing the effective carrying capacity of cuttings [2], mak- 
ing these fluids ineffective for high-temperature and high-pressure (HTHP) drilling applications. High-temperature and high-pressure applications can be classified into three categories, defined by bottom hole temperature (BHT) and pressure (BHP); HTHP when BHT is greater than $150{ }^{\circ} \mathrm{C}$ and less than $205{ }^{\circ} \mathrm{C}$ or when BHP is greater than 690 bar and less than 1,380 bar; ultraHTHP when BHT exceeds $205{ }^{\circ} \mathrm{C}$ and is less than $260{ }^{\circ} \mathrm{C}$ or when BHP exceeds 1,380 bar and is less than 2,410 bar; HTHP-hc when BHT is greater than $260{ }^{\circ} \mathrm{C}$ or when BHP is greater than 2,410 bar [6].

To extend the temperature limitation of clay-based drilling fluids, lignite is used within water-based Mt solutions to reduce fluid loss at temperatures up to $177^{\circ} \mathrm{C}[7]$. Above the temperature limitations of lignite-Mt solutions, non-aqueous drilling fluids are preferred in field applications for they are inherently lubricious and provide stable rheological properties up to operating temperatures of $204{ }^{\circ} \mathrm{C}$ [8]. However, it is desired to increase the operating limitations of clay-based drilling fluids for HTHP conditions.

To increase the temperature limitation of clay-based drilling fluids, methods have been proposed to modify surface charge to yield lesser fluid filtration loss under HTHP conditions. Haloing stabilizes colloidal fluids such as gels [9], and this study has been extrapolated to surface cation exchange within drilling fluids to promote particular surface structures [10, 11]. The use of organic polymers as viscosifiers suggests cost-effective drilling fluid improvements under HTHP conditions, but such organic polymers also have temperature limitations [12].

It has been demonstrated that micro and nanoparticles (NP) can maintain or increase the performance of drilling fluids under HTHP conditions 
[13]. Two methods of micro and NP inclusion into drilling fluids are infusion and intercalation $[14,15]$. Infusion is the mere addition of NP into the solution, without much control over the chemical and mechanical interaction between the NP and clay platelet. Micro and NP additives within drilling fluids have the potential to plug pores of subsurface formations, such as shale, preventing drilling fluid loss into said formations and subsurface fluid intrusion into the borehole without compromising the extraction of fluids from the productive horizon [16]. Intercalation is the process of modifying interlaminar cations and neutral species clays, and in this instance, of the Mt aluminosilicates with various alkalies and NP, resulting in permanently charged clay platelets. Intercalation of NP into a host matrix is a widely applied approach for modifying the structure of materials, resulting in improved chemical and physical properties. Inorganic NP have been used to stabilize fluid viscosity at high temperatures via manipulating and modifying the surface morphology and reactivity of the clay platelets [17]. Although much focus has been placed on the rheological properties of intercalatedbentonite solutions $[18,19]$, current literature does not reflect studies on the fluid filtration losses under LTLP and HTHP conditions.

This work is to address the need of concurrently studying the rheological properties and fluid filtration losses of low-solid content (LSC) bentonite fluids with and without NP additives and embedded clay hybrid solutions under LTLP and HTHP conditions. LSC bentonite fluids with iron-oxide $\left(\mathrm{Fe}_{2} \mathrm{O}_{3}\right)$ additives and two different NP embedded clay hybrids are investigated under both low-temperature low-pressure $\left(25^{\circ} \mathrm{C}, 6.9\right.$ bar $)$ and HTHP $\left(200{ }^{\circ} \mathrm{C}\right.$, 70 bar) conditions. The NP embedded clay hybrid solutions of interest are 
iron-oxide clay hybrid ( $\mathrm{ICH})$ and $\mathrm{Al}_{2} \mathrm{O}_{3}-\mathrm{SiO}_{2}$ clay hybrid $(\mathrm{ASCH})$. It will be shown that added ICH and ASCH particles in the LSC bentonite fluid system decreased filtration volumes as compared to a control bentonite solution under LTLP and HTHP conditions due to decreased filter cake permeability. Permeability of the produced filter cake is determined by the mode of interplatelet association. Furthermore, it will be demonstrated the pure addition of $\mathrm{Fe}_{2} \mathrm{O}_{3} \mathrm{NP}$ in concentration of 0.5 wt.\% with sizes of 3 and $30 \mathrm{~nm}$ had variable effects on fluid loss.

\section{Experimental set-up, drilling fluid preparation, and testing}

The experiments focused on LTLP and HTHP nanoparticle drilling fluid performance via filtration testing. Low-temperature low-pressure static filtration fluid loss testing was performed in accordance to American Petroleum Institute (API) standards [2, 20, 21]. Figures 1 a) and b) illustrate both the LTLP and HTHP filtration testing system. Five different configurations of drilling fluid solutions were prepared, each made with a five weight-percent (5.0 wt.\%) bentonite in deionized water solution, as summarized in Tab. 1; a control of 5.0 wt.\% bentonite (Sample A); 5.0 wt.\% bentonite solution with 0.5 wt.\% $3 \mathrm{~nm} \mathrm{Fe}_{2} \mathrm{O}_{3} \mathrm{NP}$ (Sample B); 5.0 wt.\% bentonite solution with 0.5 wt.\% $30 \mathrm{~nm} \mathrm{Fe}_{2} \mathrm{O}_{3} \mathrm{NP}$ (Sample C); 5.0 wt.\% bentonite solution with 0.5 wt.\% ICH (Sample D); 5.0 wt.\% bentonite solution with 0.5 wt.\% ASCH (Sample E). Table 6 provides conversions from SI to U.S. customary units.

\subsection{Synthesis of nanoparticle-clay hybrids and additive solutions}

In this study, two different types of NP-clay hybrid particles were prepared through the intercalation of metal polycations into the interlayer space 
of the clay and subsequent thermal annealing. The $\mathrm{Na}^{+}-\mathrm{Mt}$ clay (Kunipia F) used was $\mathrm{Na}_{0.35} \mathrm{~K}_{0.01} \mathrm{Ca}_{0.02}\left(\mathrm{Si}_{3.89} \mathrm{Al}_{0.11}\right)\left(\mathrm{Al}_{1.60} \mathrm{Mg}_{0.32} \mathrm{Fe}_{0.08}\right) \mathrm{O}_{10}(\mathrm{OH})_{2} \cdot \mathrm{nH}_{2} \mathrm{O}$. A detailed synthesis process of the hybrid particle fabrication can be found in [14] and [22]. A brief description follows here.

An iron polycation solution was prepared by dissolving $0.2 \mathrm{M} \mathrm{FeCl}_{3}-6 \mathrm{H}_{2} \mathrm{O}$ into $0.4 \mathrm{M} \mathrm{NaOH}$ at $70{ }^{\circ} \mathrm{C}$. The polycation solution was mechanically mixed with $\mathrm{Na}^{+}-\mathrm{Mt}$ at the same temperature to yield intercalation. Excessive polycations on the surface of the clay platelets were rinsed with deionized water. The resulting product was dried and annealed at $450{ }^{\circ} \mathrm{C}$ in a $\mathrm{N}_{2}$ atmosphere to fully transform intercalated iron polycations to embedded iron oxide NP.

The same methodology was employed for the fabrication of $\mathrm{Al}_{2} \mathrm{O}_{3}-\mathrm{SiO}_{2}$ NP. ASCH particles were created via obtaining an Al polycation solution from an aqueous solution of $0.2 \mathrm{M} \mathrm{AlCl}_{3}-6 \mathrm{H}_{2} \mathrm{O}$ and $0.2 \mathrm{M} \mathrm{NaOH}$. Upon twentyfour hours of mechanical mixing at room temperature, the solution was mixed with $\mathrm{Si}\left(\mathrm{OC}_{2} \mathrm{H}_{5}\right)_{4}$ to make an aqueous hydroxy silico-aluminum polycation solution. The hydroxy silico-aluminum polycation solution was mixed with the $\mathrm{Na}^{+}-\mathrm{Mt}$ solution, yielding intercalatation between the prepared polycations into the interlayer of the $\mathrm{Na}^{+}-\mathrm{Mt}$. The hybrid particles were then washed with deionized water, dried and annealed at $400{ }^{\circ} \mathrm{C}$ in a $\mathrm{N}_{2}$ atmosphere to fully transform the hydroxy silico-aluminum polycations to embedded aluminosilicate NP.

To form a $5.0 \mathrm{wt.} \%$ bentonite $0.5 \mathrm{wt} . \%$ hybrid solution, the hybrid particles were mixed with bentonite $\left(\mathrm{H}_{2} \mathrm{Al}_{2} \mathrm{O}_{6} \mathrm{Si}\right)$ in deionized water. These solutions were mechanically stirred for 30 minutes at $25{ }^{\circ} \mathrm{C}$. Afterwards, the solutions were sonicated for 30 minutes at $25^{\circ} \mathrm{C}$. The additive NP solutions 
were made by the simple mixing and sonication of the aforementioned weight percentages under ambient conditions.

\subsection{Rheological testing}

A viscometer equipped with a HTHP cell was used to characterize the rheological properties under different shear rates. The viscometer operated at temperatures between $25^{\circ} \mathrm{C}$ and $200{ }^{\circ} \mathrm{C}$ and pressures between 6.9 bar and 70 bar, coinciding with the LTLP and HTHP filtration environments. The shear rate varied from 1 to $200 \mathrm{~s}^{-1}$ with a step size of $4 \mathrm{~s}^{-1}$. Each step was executed for 10 seconds. Additionally, the zeta potential measurements of the 3 and $30 \mathrm{~nm} \mathrm{Fe}_{2} \mathrm{O}_{3} \mathrm{NP}$ solutions were conducted as to determine charge.

\subsection{Fluid filtration testing}

The LTLP static filtration testing was conducted using a 175 milliliter static filter press with a regulated $\mathrm{CO}_{2}$ pressurization system and reinforced filter paper. The operating pressure was 6.9 bar and the temperature was atmospheric $\left(25^{\circ} \mathrm{C}\right)$ as to replicate the testing conditions of API fluid-loss testing. The mass of the filtrate was recorded per unit time with a sample rate between five to six measurements per second using a digital balance and a personal computer. The volume was then calculated per the average density of the filtrate collected, which allowed the volume versus time to be determined. The filter cakes were gently rinsed with water to remove any excess fluid and then the thickness was measured using a micrometer.

The HTHP static filtration testing was conducted at 70 bar and $200{ }^{\circ} \mathrm{C}$ under a $\mathrm{N}_{2}$ environment. This system used the same filter press but included 
a modification to the fluid exit valve in which a two-stage valve and backpressure regulator were included. The modification allowed for a continual, variable back-pressure to be applied on the pressure cell during collection as to ensure a constant 70 bar pressure differential and to avoid evaporation of the fluid from the solution until it cooled. Adjustments were made to the total LTLP and HTHP filtration times as per the recommendation of Arthur et al. [23]. Each LTLP and HTHP test was conducted three times, with the average values reported. For HTHP testing, the volume was collected at 5, 15, 30, 60 and 90 minutes. Filter cake thickness measurements under HTHP conditions were not conducted due to the damage (dehydration and cracking) the cake sustained during cooling of the HTHP cell.

The undisturbed filter cakes of both LTLP and HTHP samples were then freeze-dried at $-45^{\circ} \mathrm{C}$ before being characterized with a field emission electron microscope. The alignment of the clay platelets was studied using SEM to observe porous matrix morphology, as has been done in other sources $[24,25,26,27]$. Images were taken in the direction of fluid flow.

\section{Results and discussion}

This section presents the rheological properties and filtration volumes of various drilling fluids under both LTLP and HTHP conditions. The performance of these novel drilling fluids is investigated in comparison to control of 5.0 wt. $\%$ bentonite solution.

\subsection{Fluid rheological properties}

Drilling fluids are typically characterized as thixotropic shear-thinning solutions, exhibiting viscosity that decreases with an increase in the shear 
rate [28]. Additionally, these fluids exhibit a yield stress, or the stress that must be applied to the fluid to initiate flow, which was found by extrapolating the shear stress versus shear rate curve to zero-shear conditions. The yield stress values are reported in Tab. 2. The shear stress versus shear rate plots for LTLP and HTHP conditions are shown in Fig. 2 a.) and b.).

Evaluating the drilling fluid as a Herschel-Bulkley fluid, the shear stress $\tau$ is

$$
\tau=\tau_{y}+K \dot{\gamma}^{n}
$$

where $\tau_{y}$ is the yield stress, $K$ is the flow consistency index, $\dot{\gamma}$ is the shear rate in $\mathrm{s}^{-1}$ and $n$ is the flow behavior index. The flow consistency $K$ and flow behavior index $n$ were found by fitting the shear stress versus shear rate data to a two-equation yield power law (Herschel-Bulkley) with 95\% confidence bounds. The flow consistency and behavior indices are presented in Tab. 2 with the yield stress.

It is noted from Fig. 2 a) that the 3 and $30 \mathrm{~nm} \mathrm{Fe} \mathrm{O}_{3}$ and $\mathrm{ICH}$ solutions exhibit a yield stress, then a decrease in stress with an increase in shear rate until a flow point is reached. This indicates the fluid appears to be in solidlike elastic state. After the flow point, the stress versus shear rate behaves according to the Herschel-Bulkley model, that is, the fluid has transitioned to a liquid-like viscous state. This is attributed to the complex interparticle interaction of additive $\mathrm{Fe}_{2} \mathrm{O}_{3} \mathrm{NP}$ and $\mathrm{ICH}$ particles within the bentonite solution, which is elaborated upon in the following paragraphs. The values for yield stress presented in Tab. 2 with parentheses indicating the modified yield stress (flow point) for which the fluid was fitted. 
The ICH and additive $\mathrm{Fe}_{2} \mathrm{O}_{3} \mathrm{NP}$ solutions have greater viscosities whereas the ASCH has a lower viscosity as compared to the bentonite control under LTLP conditions. Under HTHP conditions, the ICH solution has a greater viscosity whereas the $\mathrm{Fe}_{2} \mathrm{O}_{3}$ additive and ASCH solutions have a lower viscosity as compared to the bentonite control. The viscosity of each fluid is attributed to the mode of clay platelet interaction as brought about by surface charges, either through the addition of $\mathrm{Fe}_{2} \mathrm{O}_{3} \mathrm{NP}$ or through the introduction of intercalated clay platelets.

The addition of ICH particles into the bentonite solution promoted attraction of positives charges on the surfaces of the hybrid clay platelet with the negative charges of the bentonite platelets. This attraction was between the edge of the ICH particle and the face of a non-hybrid bentonite clay platelet (E-F) as well as attraction between the face of the hybrid iron-oxide clay platelet and the face of the non-hybrid clay platelet (face-to-face (F-F) flocculation), resulting in the formation of a rigid 3D clay platelet network. This network can be seen in Fig. 4 b.) and is graphically illustrated in the panel below image b.). This rigid clay platelet network increased the viscosity of the fluid and the resistance to flow as evidenced through an increase in the yield stress by nearly one order of magnitude, as compared to the bentonite control [14].

In contrast, embedded $\mathrm{Al}_{2} \mathrm{O}_{3}-\mathrm{SiO}_{2}$ nanoparticles promoted negative charges at the edge of the ASCH particle, increasing the negativity of the net charge of the hybrid particle. This resulted in the generation of repulsive forces between hybrid ASCH and bentonite clay platelets in the fluid system. This strong electrostatic repulsion prevented coagulation and the subsequent for- 
mation of a strong clay platelet network. This formation is illustrated in Fig. 4 c.) and is graphically illustrated in the panel below image c). Even under HTHP conditions, where typical disassociation of $\mathrm{Na}^{+}$ions within the bentonite leads to flocculation and an increase in the viscosity of the fluid system [18, 19, 34], ASCH prevented this flocculation of clay platelets, yielding a well-dispersed fluid, as evidenced by a reduction in the flow stress as compared to the bentonite control [14].

The addition of $\mathrm{Fe}_{2} \mathrm{O}_{3}$ NP induced heterocoagulation, or the assembly of different types of clay particles in a collective behavior through the introduction of an electrolyte to the clay solution, promoting a rigid structure $[11,29,30]$ and a stronger gel formation $[14,31]$. This yielded an increase in viscosity and flow stress under LTLP conditions in comparison to the bentonite control, indicating flocculation through edge-to-edge (E-E) and edgeto-face (E-F) associations. Flocculation was induced due to the imbalance of electrical charges on the surface of the clay platelet, as seen in the SEM images in Figs. 4 d.) and e.) and graphically illustrated in the panel between images d.) and e.). The $\mathrm{Fe}_{2} \mathrm{O}_{3} \mathrm{NP}$ exhibit positive charges in an aqueous environment and will attract the negatively charged faces of the bentonite clay platelets. Under HTHP conditions, the viscosity and flow stress of the $\mathrm{Fe}_{2} \mathrm{O}_{3}$ solutions minimally increased in comparison to the bentonite control, indicating flocculation via the same associations between edge and face as seen under LTLP conditions [14].

It is evident the addition of $0.5 \mathrm{wt} \% 3 \mathrm{~nm} \mathrm{Fe} \mathrm{O}_{3} \mathrm{NP}$ had a more substantial effect on viscosity and flow stress of the bentonite solution than did the 30 nm counterpart. The viscosity increased $194 \%$ and $40 \%$ in comparison to the 
bentonite control for the $3 \mathrm{~nm}$ samples under LTLP and HTHP conditions, respectively, in comparison to the $66 \%$ and $5 \%$ increase in LTLP and HTHP viscosities of the $30 \mathrm{~nm}$ samples. The flow stresses increased on the same order of magnitude as the viscosities for both samples under both conditions in comparison to the control [14]. The reason for an increase in viscosity and flow stress is how the NP associate with the clay platelets, with themselves, and the subsequent interaction between clay platelets, as evidenced by zeta potential (ZP) measurements.

The 3 and $30 \mathrm{~nm} \mathrm{Fe}_{2} \mathrm{O}_{3} \mathrm{NP}$ with concentration of $5 \mathrm{mg} / 1 \mathrm{~mL}$ in DI water with a $\mathrm{pH}$ of 8.2-8.6 have $\mathrm{ZP}$ values of $15.22 \pm 0.78$ and $17.44 \pm 0.42$ respectively, indicating unstable colloidal solutions with a high potential of aggregation (in the chemistry definition). Stable colloidal solutions typically have absolute ZP values greater than 30. In 5.0 wt.\% bentonite solution, the 0.5 wt. $\% 3$ and $30 \mathrm{~nm} \mathrm{Fe}_{2} \mathrm{O}_{3}$ solutions have $\mathrm{ZP}$ values of $-23.50 \pm 1.73$ and $7.53 \pm 2.00 \mathrm{mV}$ and $\mathrm{pH}$ values of 8.64 and 8.82 . In comparison, the $\mathrm{ZP}$ of the $5.0 \mathrm{wt} \%$ bentonite solution was found to be $-7.06 \pm 2.64$. Typically, there is a large negative charge generated in aqueous Mt solutions due to substitution of $\mathrm{Si}^{4+}$ for $\mathrm{Al}^{3+}, \mathrm{Mg}^{2+}$, and $\mathrm{Fe}^{2+}$ in the Mt aluminosilicate layers. However, based on the magnitude of the ZP for the 5.0 wt.\% bentonite solution, there is not enough electrostatic repulsion within the colloidal solution to keep it well-dispersed, hence the onset of flocculation. The larger magnitude of the $\mathrm{ZP}$ of the $3 \mathrm{~nm} \mathrm{Fe}_{2} \mathrm{O}_{3} \mathrm{NP}$ solution indicates greater stability than the bentonite control and $30 \mathrm{~nm} \mathrm{Fe}_{2} \mathrm{O}_{3}$ solution.

The relative stability of the $3 \mathrm{~nm} \mathrm{Fe}_{2} \mathrm{O}_{3} \mathrm{NP}$ solution is due to the larger surface area to volume ratio of the $3 \mathrm{~nm} \mathrm{Fe}_{2} \mathrm{O}_{3} \mathrm{NP}$ as compared to the $30 \mathrm{~nm}$ 
$\mathrm{Fe}_{2} \mathrm{O}_{3}$ NP. A larger surface area to volume ratio leads to stronger electrical attraction with the negatively charged face of the bentonite clay platelet. Furthermore, for the same weight percent, there are more $3 \mathrm{~nm} \mathrm{Fe}{ }_{2} \mathrm{O}_{3} \mathrm{NP}$ participating in attraction with the betonite clay platelet. Additionally, the $3 \mathrm{~nm} \mathrm{Fe}_{2} \mathrm{O}_{3}$ NP experience aggregation between NP due to electrostatic attraction. The mutual attraction between NP and clay platelet surfaces results in a heterocoagulated structure as seen in bottom middle panel of Fig. 4. The $3 \mathrm{~nm} \mathrm{Fe} \mathrm{F}_{3}$ heterocoagulated bentonite clay platelets are positively charged, repelling like structures and platelets within the solution and thus the solution exhibits better dispersion (higher $\mathrm{ZP}$ value) and stability than the $30 \mathrm{~nm} \mathrm{Fe} \mathrm{O}_{3}$ and bentonite solutions.

The $\mathrm{pH}$ values of the 3 and $30 \mathrm{~nm} \mathrm{Fe} \mathrm{O}_{3}$ NP solutions are 8.64 and 8.82. Lower $\mathrm{pH}$ values $(<7.5)$ lead to $\mathrm{E}-\mathrm{E}$ and $\mathrm{E}-\mathrm{F}$ flocculation due to the minimization of surface charge imbalance [32]. Increasing the $\mathrm{pH}$ leads to an increase in F-F associations, where the clay platelets aggregate, forming a linked structure [33]. This linked structure is able to trap more water between the layers, increasing the visocity, yield stress and subsequently decreasing fluid filtration volume. The addition of the 3 and $30 \mathrm{~nm} \mathrm{Fe}{ }_{2} \mathrm{O}_{3} \mathrm{NP}$ did not substantially affect the $\mathrm{pH}$ of the solution as to increase E-E or E-F flocculation, nor did they induce F-F flocculation. Thus, the heterocoagulated structure increased the viscosity and yield stress, and as will be presented in the following section, LTLP fluid filtration loss.

Increasing the temperature and pressure of the drilling fluid changes the viscosity, and thus the rheological properties and subsequent fluid filtration performance. It has been proposed that elevated temperatures induce the 
dissocation of $\mathrm{Na}^{+}$from the surface of bentonite, leading to an increase in viscosity $[18,19,34]$, as evidenced by Figs. 3 a) and b). For example, Samples A through E experienced an 18.9-, 9.0-, 11.9-, 5.5-, and 5.1-fold increase in apparent viscosity when tested under HTHP as compared to LTLP conditions, respectively. The effect of pressure, although acting to increase the viscosity via increased particle interaction, is not as great as temperature $[35,36]$. From prior work, it can be seen that the effect of pressure is less than temperature on the viscosity of betonite, ICH and ASCH solutions [14].

\subsection{Fluid filtration properties}

\subsection{1. $L T L P$}

Figure 5 depicts the behavior of the entirety of the bentonite solutions fluid filtrate loss per unit square-root of time in comparison to the control under LTLP conditions. Table 3 summarizes the filtration volumes of the fluids under both LTLP and HTHP conditions. The fluid filtrate loss is plotted against the square root of time for the solution of Darcy's Law (Eqn. 2) is in the form of Eqn. 3 and additionally, after the spurt loss, the fluid filtrate loss becomes linear with respect to the square root of filtration time. Fitting the filtration volume versus times as per the power law yields exponent values in the range of 0.49 to 0.51 as seen in Tab. 4, which do not reflect the idealized value of 0.5 from Darcy's Law.

The ICH and ASCH fluids exhibit the least fluid loss, respectively. The ICH and ASCH solutions exhibited a $37 \%$ and 19\%, 36\% and 18\%, and $34 \%$ and $17 \%$ reduction in 30-, 60- and 90-minute fluid filtration volumes as compared to the 5.0 wt.\% bentonite, respectively. Darcy's Law describes fluid filtrate volumes $d V$ as a function of time $d t$, cross-sectional area $A$, 
permeability $\kappa$, pressure differential $\Delta P$, viscosity $\eta$ and filter cake thickness $t_{c}$, which is expressed as

$$
\frac{d V}{d t}=\frac{\kappa \Delta P A}{\eta t_{c}} .
$$

The solution to Darcy's Law as a function of the aforementioned variables is expressed as

$$
V_{f}=A \sqrt{\frac{2 t \kappa \Delta P}{\eta}\left(\frac{f_{s c}}{f_{s m}}-1\right)},
$$

where $f_{s m}$ is the volume fraction of solids within the mud and $f_{s c}$ is the volume fraction of solids within the cake. To calculate the permeability of each solution's filter cake, the following assumptions were made; the crosssectional area is constant at $45 \mathrm{~cm}^{2}$; the pressure difference is constant at 6.9 bar; the viscosity of the fluid of interest is water taken at $25^{\circ} \mathrm{C}$; the filter cake thickness, although a function of time, is assumed constant and is taken as the reported final measured thickness as seen in Tab. 5 .

It is evident from Tab. 5 that the permeability of the additive 3 and 30 $\mathrm{nm} \mathrm{Fe}_{2} \mathrm{O}_{3}$ filter cakes prepared under LTLP conditions are $66 \%$ and $26 \%$ higher than the bentonite control, respectively. As observed from Fig. 5, the additive $\mathrm{Fe}_{2} \mathrm{O}_{3}$ NP bentonite solutions increased fluid loss as compared to the control, which is attributed to the increase in permeability of the filter cake due to the hetercoagulated structure. Additionally, an increase in filtrate volume would yield an increase in filter cake thickness as seen in Tab. 5. While the size of the $\mathrm{Fe}_{2} \mathrm{O}_{3} \mathrm{NP}$ increased from 3 to $30 \mathrm{~nm}$, the solution exhibited a small decrease in fluid filtrate volume which is attributed to a slight 
decrease in filter cake permeability. The heterocoagulated formation, which formed a strong clay platelet network, did not experience compaction during filtration testing, thus the high permeability filter cake. As the particle size increased, the degree of heterocoagulation decreased, reducing the filter cake permeability and filtrate volume.

The ICH and ASCH solutions produced filter cakes of lesser permeability which reflect a $17 \%$ and $23 \%$ reduction in $\kappa$ in comparison to the bentonite control, as provided in Tab. 5. The embedded $\mathrm{Fe}_{2} \mathrm{O}_{3} \mathrm{NP}$ promoted positive charges at the edge of the particles, bringing about strong attractive forces between the positively charged edge of $\mathrm{ICH}$ particles and negatively charged face of clay particles, exhibiting a house-of-cards structure. Strongly cross-linked formations provide more rigid structure which exhibit apparent low permeability, explaining a decrease in the filtrate volumes. In contrast, embedded $\mathrm{Al}_{2} \mathrm{O}_{3}-\mathrm{SiO}_{2} \mathrm{NP}$ promote negative charges at the edge of the particle, leading to a repulsive force between $\mathrm{ASCH}$ and bentonite clay platelets. This electrostatic repulsion prevented clay platelet coagulation, and additionally maintained a well-dispersed fluid. The permeability decreased due to subsequent compaction of the well-dispersed, non-coagulated platelets, as evidenced by the filter cake thickness which was less than the bentonite control, yielding a reduction in filtrate volume.

The effect of intercalation and additive NP is illustrated by the SEM images in Fig. 4. Figure 4 a) shows the control bentonite filter cake, whereas Figs. 4 b) and c) show the ICH and ASCH filter cakes. The ICH filter cake exhibits predominant F-F association through electrostatic attraction between the face of the hybrid iron-oxide clay platelet and the face of the 
non-hybrid clay platelet. This resulted in the formation of a rigid 3D clay platelet network, which increased the resistance to flow and decreased the permeability. The ASCH filter cake as seen in Fig. 4 c) is the result of a strong cross-linked clay platelet network formation that is a result of strong electrostatic repulsion between ASCH and bentonite clay platelets. This strong network formation reduced the porosity and subsequent permeability.

Figures 4 d.) and e.) shows the SEM images, concurrent with literature [37], and the schematic illustration representing hetercoagulated formations of $\mathrm{Fe}_{2} \mathrm{O}_{3} \mathrm{NP}$ and clay platelets. Randomly shaped and empty spaces are created between the particles and thus filtration easily occurs through these pores, leading to higher permeability values and fluid filtrate volumes.

\subsection{2. $H T H P$}

Figure 6 a.) and b.) depict the behavior of the hybrid (ICH and ASCH) and 3 and $30 \mathrm{~nm}$ additive $\mathrm{Fe}_{2} \mathrm{O}_{3}$ bentonite solutions fluid filtrate loss per unit square-root of time under HTHP conditions, respectively, along with the results being summarized in Table 3 .

The ICH and ASCH added fluids exhibit the least fluid loss in comparison to the bentonite control, with a reduction in fluid filtrate volumes by $47 \%$ and $20 \%$ for the 30 -minute, $43 \%$ and $23 \%$ for the 60 -minute and $35 \%$ and $26 \%$ for the 90-minute tests, respectively. With an increase in temperature, the ICH filter cake retained the strong positive charges, which attracted the negative charges on the faces of the bentonite platelets, thus creating a rigid house-ofcards structure with a high viscosity. The house-of-cards structure allowed for the formation of a filter cake with low-permeability characteristics. The permeability of the ICH filter cake was decreased due to reduced pore sizes, 
which is attributed to the collapse of the hybrid and non-hybrid clay platelets via the strong attraction between hybrid and bentonite platelets faces (FF). This low porosity and low permeability filter cake exhibited low filtrate volume in comparison to the bentonite control.

The negative charge of the ASCH clay platelets repulsed the bentonite clay platelets and acted as a deflocculant, promoting clay platelet dispersion within the solution at elevated temperatures $[2,14]$. This dispersion resulted in the production of a low porosity and low permeability filter cake, resulting in lesser fluid filtrate volume as compared to the bentonite control.

Figure 6 b.) depicts the filtration volumes of bentonite fluids containing $\mathrm{Fe}_{2} \mathrm{O}_{3}$ additive NP under HTHP conditions. Contrasting to the indications in Fig. 4, under HTHP conditions, $\mathrm{Fe}_{2} \mathrm{O}_{3}$ additive NP solutions showed a decrease in fluid filtration volume as compared to the control bentonite fluid. Elevated temperatures induce flocculation of clay platelets and the dissocation of $\mathrm{Na}^{+}$from the surface of bentonite; as $\mathrm{Na}^{+}$concentrations increase, pre-existing network formations collapse and the solution became flocculated, creating a high porosity and high permeability filter cake, as evidenced by a $330 \%, 286 \%$ and $246 \%$ increase in the 30-, 60- and 90-minute HTHP filtration volumes of the $5.0 \mathrm{wt} \%$ bentonite solution as compared to LTLP. However, the $\mathrm{Fe}_{2} \mathrm{O}_{3}$ NP replaced the disassociated $\mathrm{Na}^{+}$and allowed the clay platelet to retain a positive charge along the edge; this retention of positive edge charge kept the clay platelets dispersed and deflocculated. Thus, the deflocculated solution exhibit a low porosity and low permeability filter cake, thus less filtrate volume in comparison to the bentonite contol.

The filter cake permeability and subsequent fluid filtration is influenced 
by the clay platelet interaction under HTHP conditions; ICH added solutions exhibit rigid networks and low permeability filter cakes due to the strong network formation between positively charged hybrid platelets and negatively charged bentonite edges, thus low filtration volumes; ASCH added solutions exhibit good dispersion due to repulsion generated between negatively charged hybrid particles and negatively charged bentonite faces, thus minimal clay platelet network formation and low permeability filter cakes; additive $\mathrm{Fe}_{2} \mathrm{O}_{3}$ solutions are deflocculated due to the replacement of dissociate $\mathrm{Na}^{+}$cations with $\mathrm{Fe}_{2} \mathrm{O}_{3} \mathrm{NP}$, leading to a solution that yield low permeability filter cakes.

This work illustrates how modifying the surface charge of clay-based drilling fluids via intercalation and NP addition can alter the rheological properties and fluid filtration characteristics of conventional drilling muds under LTLP and HTHP conditions.

\section{Conclusions}

The rheological properties and fluid filtration performance of low solid content bentonite fluids containing iron-oxide $\left(\mathrm{Fe}_{2} \mathrm{O}_{3}\right)$ additives and nanoparticle (NP) intercalated clay hybrids under low-temperature low-pressure (LTLP: $25^{\circ} \mathrm{C}, 6.9$ bar) and high-temperature high-pressure (HTHP: $200^{\circ} \mathrm{C}, 70$ bar) conditions were investigated.

The iron-oxide clay hybrid (ICH) added hybrid solution exhibited less fluid filtrate as compared to the bentonite control under LTLP and HTHP conditions. ICH added solutions exhibited strong cross-linked and coagulated platelet networks under LTLP and HTHP conditions. The cross-linked 
platelet network was less sensitive to pressure and temperature which resulted in less permeable filter cakes, reducing fluid filtrate volumes under LTLP and HTHP conditions.

The LTLP and HTHP fluid filtrate volumes of the aluminosilicate clay hybrid (ASCH) added hybrid solutions were less than the bentonite control due to the reduced permeability of the filter cakes. The effect on permeability is attributed to the strong electrostatic repulsion between the hybrid particles and clay platelets which provided good dispersion and prevented coagulation and flocculation.

The pure addition of 0.5 wt. $\% 3$ and $30 \mathrm{~nm} \mathrm{Fe}_{2} \mathrm{O}_{3} \mathrm{NP}$ in 5.0 wt.\% bentonite solutions increased the fluid filtrate volume under LTLP conditions as compared to the 5.0 wt.\% bentonite control. $\mathrm{Fe}_{2} \mathrm{O}_{3} \mathrm{NP}$ promoted hetercoagulation of clay platelets which resulted in the formation of a permeable filter cake during filtration testing. Furthermore, the pure addition of $\mathrm{Fe}_{2} \mathrm{O}_{3} \mathrm{NP}$ to the bentonite solution tested under HTHP reduced fluid filtrate volumes as compared to the bentonite control. The fluid filtrate volume decreased at elevated temperatures because $\mathrm{Fe}_{2} \mathrm{O}_{3} \mathrm{NP}$ replaced dissociated $\mathrm{Na}^{+}$cations, deflocculating the solution which yielded a low permeability filter cake

SEM images of the $\mathrm{Fe}_{2} \mathrm{O}_{3}$ additive solutions showed rigid, porous structures under LTLP conditions and less porous structures under HTHP conditions. SEM images of the ICH added solution filter cakes showed a semiporous cross-linked structure under both LTLP and HTHP conditions, and those of the ASCH added solutions filter cakes showed random, coagulated structures under both LTLP and HTHP condition. 


\section{Nomenclature}

449

450

451

453

454

455

\section{Variables}

A area, $\mathrm{m}^{2}$

$t_{c} \quad$ cake thickness, $m$

$K$ flow consistency index, Pa-s

$n$ flow behavior index, dimensionless

$\Delta P$ pressure differential, $\mathrm{Pa}$

$t$ time, $\mathrm{s}$

$T$ temperature, ${ }^{\circ} \mathrm{C}$

$V \quad$ volume, $\mathrm{mL}$

\section{Greek symbols}

$\eta$ flow behavior index, dimensionless

$\dot{\gamma}$ shear rate, $\mathrm{s}^{-1}$

$\kappa$ permeability, $\mathrm{D}$

$\tau$ shear or yield stress, $\mathrm{Pa}$

\section{Subscripts}

30 30-minute

60 60-minute

90 90-minute

c cake, $\mathrm{m}$

y yield

\section{Acknowledgements}

This work was supported by the Department of Energy. 
Table 1: Abbreviated Sample Names.

\begin{tabular}{|c|c|}
\hline Sample & Sample Abbreviation \\
\hline 5.0 wt.\% Bentonite & Sample A \\
5.0 wt.\% Bentonite with 0.5 wt. $\% 3 \mathrm{~nm} \mathrm{Fe}_{2} \mathrm{O}_{3}$ & Sample B \\
5.0 wt.\% Bentonite with 0.5 wt. $\% 30 \mathrm{~nm} \mathrm{Fe}_{2} \mathrm{O}_{3}$ & Sample C \\
5.0 wt.\% Bentonite with 0.5 wt.\% ICH & Sample D \\
5.0 wt.\% Bentonite with 0.5 wt.\% ASCH & Sample E \\
\hline
\end{tabular}

Table 2: The yield stress $\tau_{y}$, flow consistency index $K$ and flow behavior index $n$ of all drilling fluids under LTLP conditions treated as Herschel-Bulkley fluids.

\begin{tabular}{|c|c|c|c|}
\hline Sample & $\tau_{y}[\mathrm{~Pa}]$ & $K[\mathrm{~Pa}-\mathrm{s}]$ & $n$ \\
\hline A & 1.04 & $0.022 \pm 0.001$ & $0.890 \pm 0.001$ \\
$\mathrm{~B}$ & $2.43(1.436 \pm 0.046)$ & $0.060 \pm 0.007$ & $0.742 \pm 0.020$ \\
$\mathrm{C}$ & $2.03(1.403 \pm 0.026)$ & $0.033 \pm 0.003$ & $0.817 \pm 0.015$ \\
$\mathrm{D}$ & $9.85(3.165 \pm 1.411)$ & $3.041 \pm 1.07$ & $0.225 \pm 0.040$ \\
$\mathrm{E}$ & 0.25 & $0.011 \pm 0.002$ & $0.856 \pm 0.030$ \\
\hline
\end{tabular}


Table 3: LTLP and HTHP fluid filtrate volumes $V$ (all volumes are in [mL] and are reported at time in minutes).

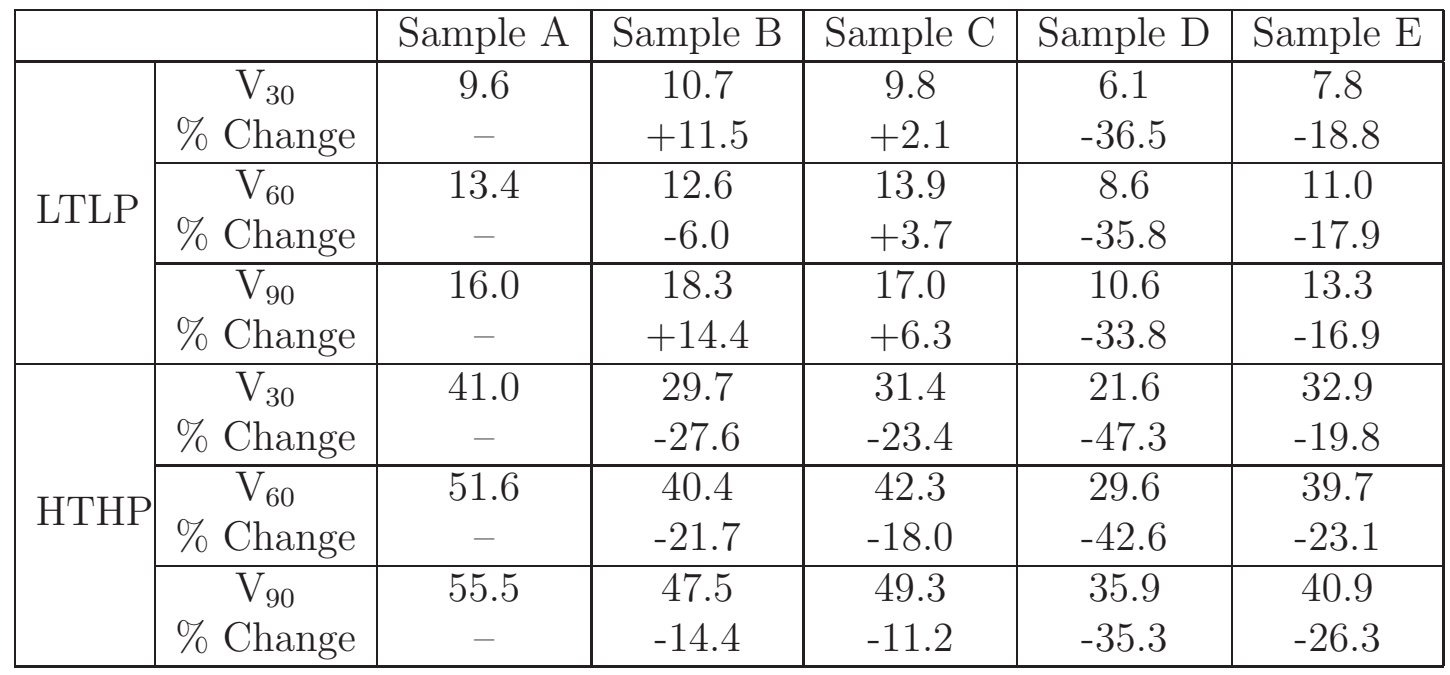

Table 4: Exponential fit of filtration data under LTLP and HTHP conditions.

\begin{tabular}{|c|c|c|}
\hline Sample & LTLP & HTHP \\
\hline A & $0.49 \pm 1 \mathrm{e}-4$ & $0.40 \pm 0.127$ \\
B & $0.50 \pm 1 \mathrm{e}-4$ & $0.50 \pm 0.078$ \\
C & $0.51 \pm 1 \mathrm{e}-4$ & $0.32 \pm 0.105$ \\
D & $0.51 \pm 1 \mathrm{e}-4$ & $0.48 \pm 0.101$ \\
E & $0.49 \pm 1 \mathrm{e}-4$ & $0.44 \pm 0.034$ \\
\hline
\end{tabular}


Table 5: Permeability $\kappa$ calculated from Darcy's Law from filter cake thicknesses $t_{c}$ under LTLP conditions.

\begin{tabular}{|c|c|c|}
\hline Sample & $t_{c}[\mathrm{~cm}]$ & $\kappa 10^{-3}[\mathrm{mD}]$ \\
\hline $\mathrm{A}$ & 3.82 & 3.33 \\
$\mathrm{~B}$ & 5.55 & 5.53 \\
$\mathrm{C}$ & 4.53 & 4.18 \\
$\mathrm{D}$ & 4.82 & 2.77 \\
$\mathrm{E}$ & 3.54 & 2.57 \\
\hline
\end{tabular}

Table 6: Conversion between metric and U.S. customary units

\begin{tabular}{|c|c|c|}
\hline Physical Quantity & Metric Units & U.S. Customary Units \\
\hline Length & $1 \mathrm{~m}=$ & 39.3701 inches \\
Pressure & $1 \mathrm{bar}=$ & $14.5038 \mathrm{psi}$ \\
Temperature & $1{ }^{\circ} \mathrm{C}=$ & $\left({ }^{\circ} \mathrm{F}-32\right) \cdot \frac{5}{9}$ \\
Viscosity & $1 \mathrm{~Pa}-\mathrm{s}=$ & 24.1909 pound $/$ foot-hour \\
Volume & $1 \mathrm{~mL}=$ & 0.0338 fluid ounce \\
\hline
\end{tabular}




\section{References}

[1] P. F. Luckham, S. Rossi, The colloidal and rheological properties of bentonite suspensions, Advances in Colloid and Interface Science 82 (13) (1999) 43-92.

[2] A. T. Bourgoyne Jr., M. E. Chenevert, K. K. Millheim, F. S. Young Jr., Applied Drilling Engineering, vol. 2, Society of Petroleum Engineers, 1986.

[3] D. H. Larsen, Use of clay in drilling fluids, Clay and Clay Technologies (1955) 269-281.

[4] H. Darley, G. R. Gray, Composition and properties of drilling and completion fluids, Gulf Professional Publishing, 5 edn., 1988.

[5] V. C. Kelessidis, C. Tsamantaki, N. Pasadakis, E. Repouskou, E. Hamilaki, Permeability, porosity and surface characteristics of filter cakes from water bentonite suspensions, $6^{\text {th }}$ International Conference on Advances in Fluid Mechanics, 2006.

[6] A. Belani and S. Orr, Management-A Systematic Approach to Hostile Environments, Journal of Petroleum Technology, 60 (7) (2008).

[7] V. C. Kelessidis, C. Tsamantaki, A. Michalakis, G. E. Christidis, P. Makr, K. Papanicolaou, A. Foscolos, Greek lignites as additives for controlling filtration properties of water-bentonite suspensions at high temperatures, Fuel 86 (78) (2007) 1112-1121. 
[8] M. Mas, T. Tapin, R. Mácrquez, R. Gabay, Z. Negrín, C. Díaz, L. Bejarano, A new high-temperature oil-based drilling fluid, Latin American and Caribbean Petroleum Engineering Conference, Society of Petroleum Engineers, 1999.

[9] V. Tohver, J. E. Smay, A. Braem, P.V. Braun, J. A. Lewis, Nanoparticle halos: a new colloid stabilization mechanism, Proceedings of the National Academy of Sciences 98 (16) (2001) 8950-8954.

[10] E. Tombácz, J. Balázs, J. Lakatos, F. Szántó, Influence of the exchangeable cations on stability and rheological properties of montmorillonite suspensions, Colloid and Polymer Science 267 (1989) 1016-1025.

[11] E. Tombácz, C. Czanaky, E. Illés, Polydisperse fractal aggregate formation in clay mineral and iron oxide suspensions, $p H$ and ionic strength dependence, Colloid and Polymer Science 279 (2001) 484-492.

[12] V. Mahto, V. Sharma, Rheological study of a water based oil well drilling fluid, Journal of Petroleum Science and Engineering 45 (12) (2004) 123128.

[13] J. C. Baird and J. Y. Walz. The effects of added nanoparticles on aqueous kaolinite suspensions: II. Rheological effects, Journal of Colloid and Interface Science 306 (2) (2007) 411-420.

[14] Y. Jung, Y.-H. Son, J.-K. Lee, T. X. Phuoc, Y. Soong, M. K. Chyu, Rheological behavior of clay nanoparticle hybrid-added bentonite suspensions: specific role of hybrid additives on the gelation of clay-based fluids, ACS Applied Materials and Interfaces 3 (9) (2011) 3515-3522. 
[15] T. Huang, J. B. Crews, G. Agrawal, Nanoparticle psuedocrosslinked micellar fluids: optimal solution for fluid-loss control with internal breaking, SPE International Symposium and Exhibition on Formation Damage Control, Society of Petroleum Engineers, 2010.

[16] J. T. Srivatsa, M. B. Ziaja, An experimental investigation on use of nanoparticles as fluid loss additives in a surfactant-polymer based drilling fluids, International Petroleum Technology Conference, 2012.

[17] T. Huang, J. B. Crews, Nanotechnology applications in viscoelastic surfactant stimulation fluids, SPE Production and Operations 23 (4) (2008) $512-517$.

[18] E. Tombáccz, M. Szekeres, Colloidal behavoir of aqueous montmorillonite suspensions: the specific role of $p H$ in the presence of indifferent electrolytes, Applied Clay Science 27 (12) (2004) 75-94.

[19] S. Laribi, J.-M. Fleureau, J.-L. Grossiord, N. Kbir-Ariguib, Effect of $p H$ on the rheological behavior or pure and interstratified smectite clays, Clays and Clay Minerals 54 (1) (2006) 29-37.

[20] Spec 13A, Specification for Drilling-Fluid Materials, American Petroleum Institute, Production Department, Washington, DC, 15 edn., 1993.

[21] Recommended practice standard procedure for laboratory testing drilling fluids, API recommended practice, American Petroleum Institute, Production Department, Washington, DC, 1990. 
[22] Y.-H. Son, J.-K. Lee, Y. Soong, D. Martello, M. Chyu, Structure property correlation in iron oxide nanoparticle clay hybrid materials, Chemistry of Materials 22 (7) (2010) 2226-2232.

[23] K. Arthur, J. Peden, The evaluation of drilling fluid filter cake properties and their influence on fluid loss, International Meeting on Petroleum Engineering, Society of Petroleum Engineers, Tianjin, China, 1988.

[24] K. E. Porte, A basic scanning electron microscope study of drilling fluids, SPE Formation Damage Symposium, Society of Petroleum Engineers, 1980.

[25] L. Hartmann, M. Özerler, C. Marx, H.-J. Neumann, Analysis of mudcake structures formed under simulated borehole conditions, SPE Drilling Engineering 3 (4) (1988) 395-402.

[26] J. Plank, A. Trostberg, F. Gossen, Visualization of fluid-loss polymers in drilling-mud filter cakes, SPE Drilling Engineering 6 (3) (1991) 203-208.

[27] M. Chenevert, J. Huycke, Filter cake structure analysis using the scanning electron microscope, Tech. Rep., Society of Petroleum Engineers, 1991.

[28] S. Livescu, Mathematical modeling of thixotropic drilling mud and crude oil flow in wells and pipelinesA review, Journal of Petroleum Science and Engineering 98 (2012) 174-184.

[29] U. Brandenburg, G. Lagaly, Rheological properties of sodium montmorillonite dispersions, Applied Clay Science 3 (3) (1988) 263-279. 
[30] G. Lagaly, Principles of flow of kaolin and bentonite dispersions, Applied Clay Science 4 (2) (1989) 105-123.

[31] I. C. Callaghan, R. H. Ottewill, Interparticle forces in montmorillonite gels, Faraday Discuss. Chem. Soc. 57 (1974) 110-118.

[32] J. Stawinksi, J. Wierzchos and M. T. García González, Influence of calcium and sodium concentration on the microstructure of bentonite and kaolin, Clays and Clay Minerals 38 (1990) 617-622.

[33] H. Vali and L. Bachmann. Ultrastructure and flow behavior of colloidal smectite dispersions, Journal of Colloid and Interface Science 126 (1) (1988) 278-291.

[34] M. Ramos-Tejada, F. Arroyo, R. Perea, J. Durán, Scaling behavior of the rheological properties of montmorillonite suspensions: correlation between interparticle interaction and degree of flocculation, Journal of Colloid and Interface Science 235 (2) (2001) 251-259.

[35] N. J. Alderman, A. Gavignet, D. Cuillot, G. C. Maitland and others, High-temperature high-pressure rheology of water-based muds, SPE Annual Technical Conference and Exhibition, Society of Petroleum Engineers, 1988.

[36] B.J. Briscoe, P. F. Luckham, and S. R. Ren, The properties of drilling muds at high pressures and high temperature, Philosophical Transactions of the Royal Society of London. Series A: Physical and Engineering Sciences 348 (1687) (1994) 179-207. 
568 [37] H. van Olphen, Internal mutual flocculation in clay suspensions, Journal 569 of Colloid Science 19 (4) (1964) 313-322. 
570

\section{Figure Captions}

1. Low-temperature low-pressure and high-temperature high-pressure filtration testing assemble with a) HTHP experimental set-up and b) schematic of LTLP and HTHP equipment.

2. Shear stress vs. shear rate of various drilling fluids under a.) LTLP and b.) HTHP conditions. Solid lines indicate Herschel-Bulkley fits, based upon the information provided in Tab. 2.

3. Viscosity vs. shear rate of various drilling fluids under a.) LTLP and b.) HTHP conditions.

4. SEM of LTLP filter cakes: a.) Sample A b.) Sample D c.) Sample E d.) Sample B e.) Sample C with corresponding clay platelet interaction illustrations.

5. Cumulative LTLP fluid filtration volumes as a function of square-root of time.

6. Cumulative a.) hybrid and b.) additive HTHP fluid filtration volumes as a function of square-root of time. 

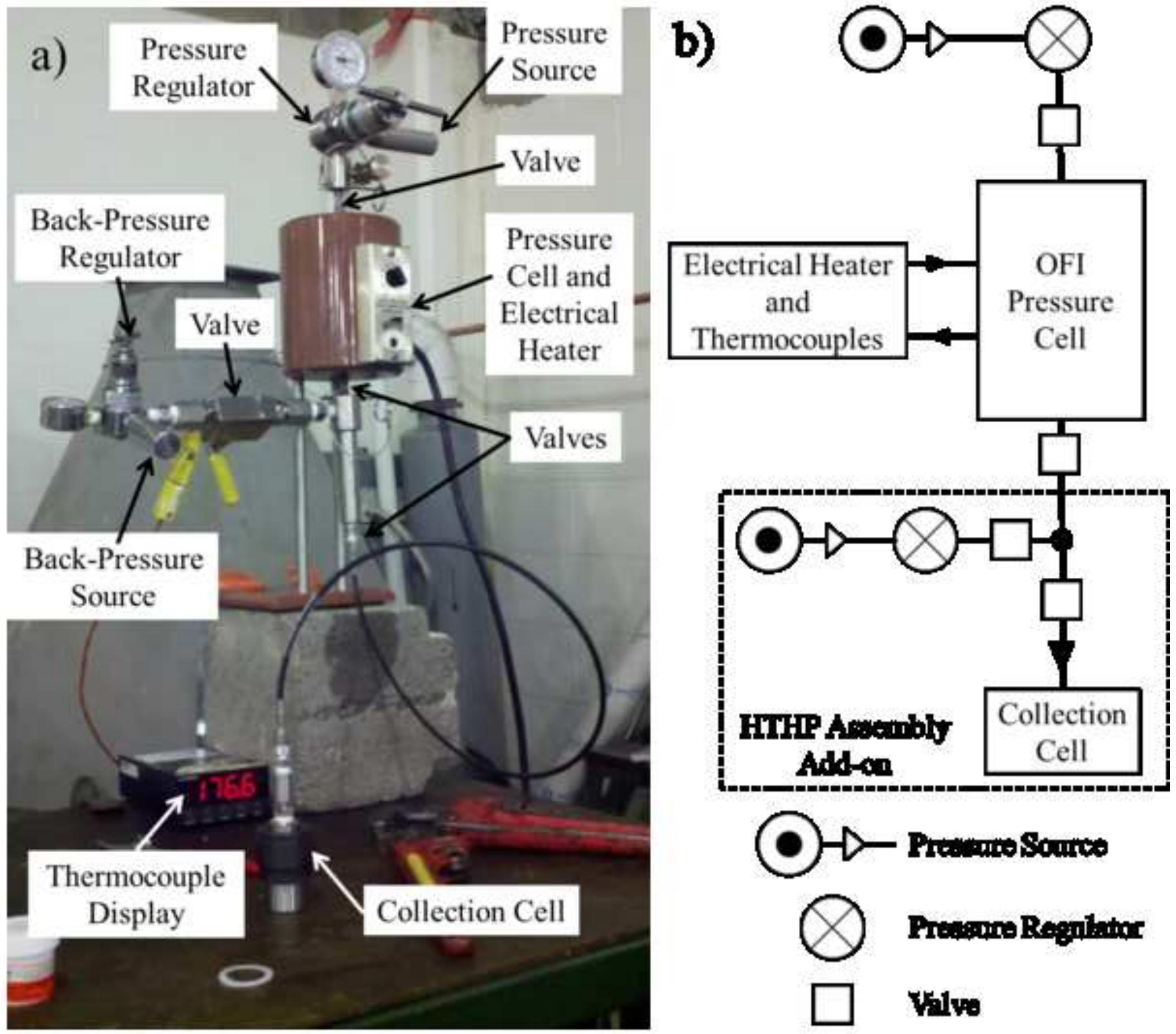


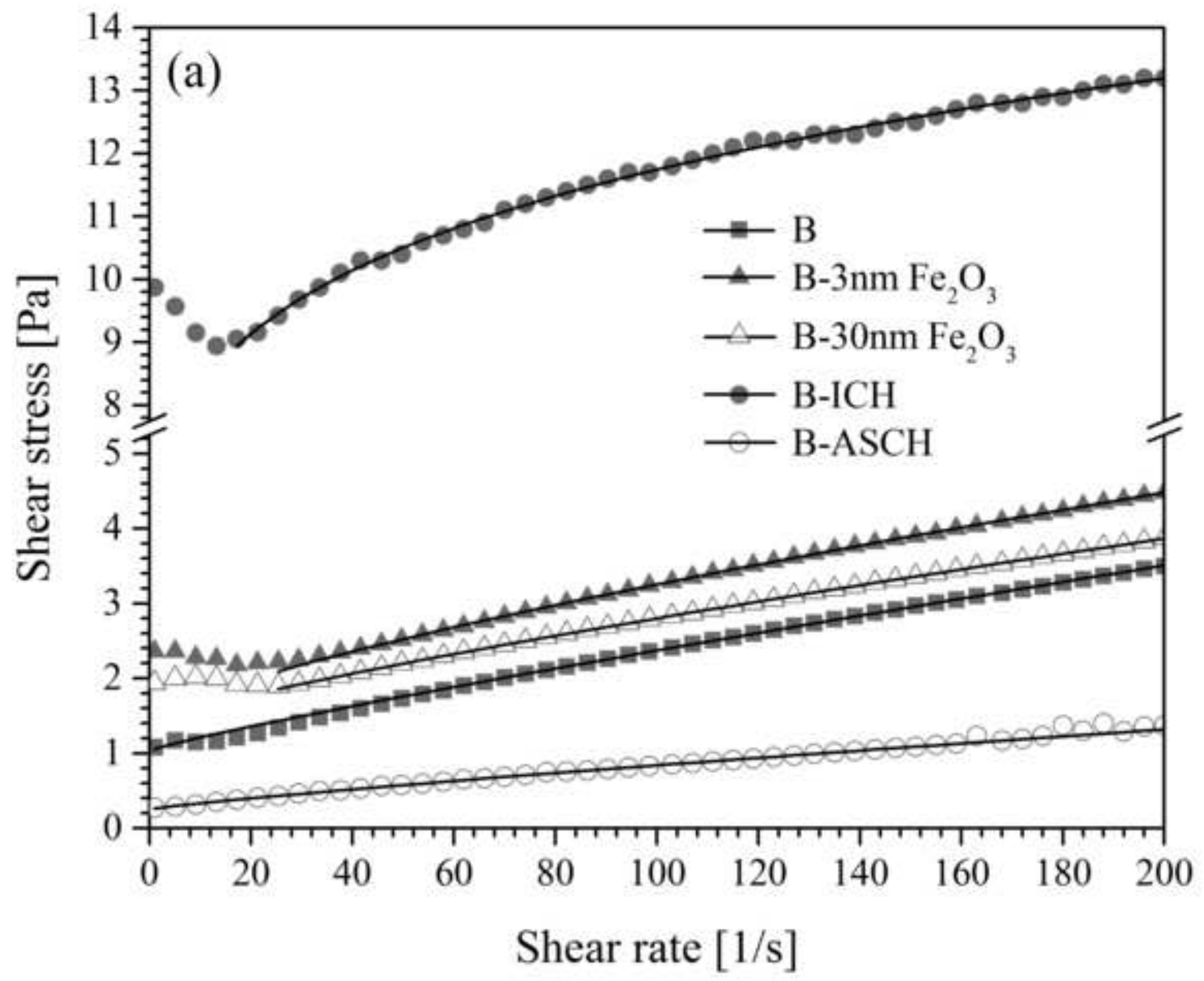




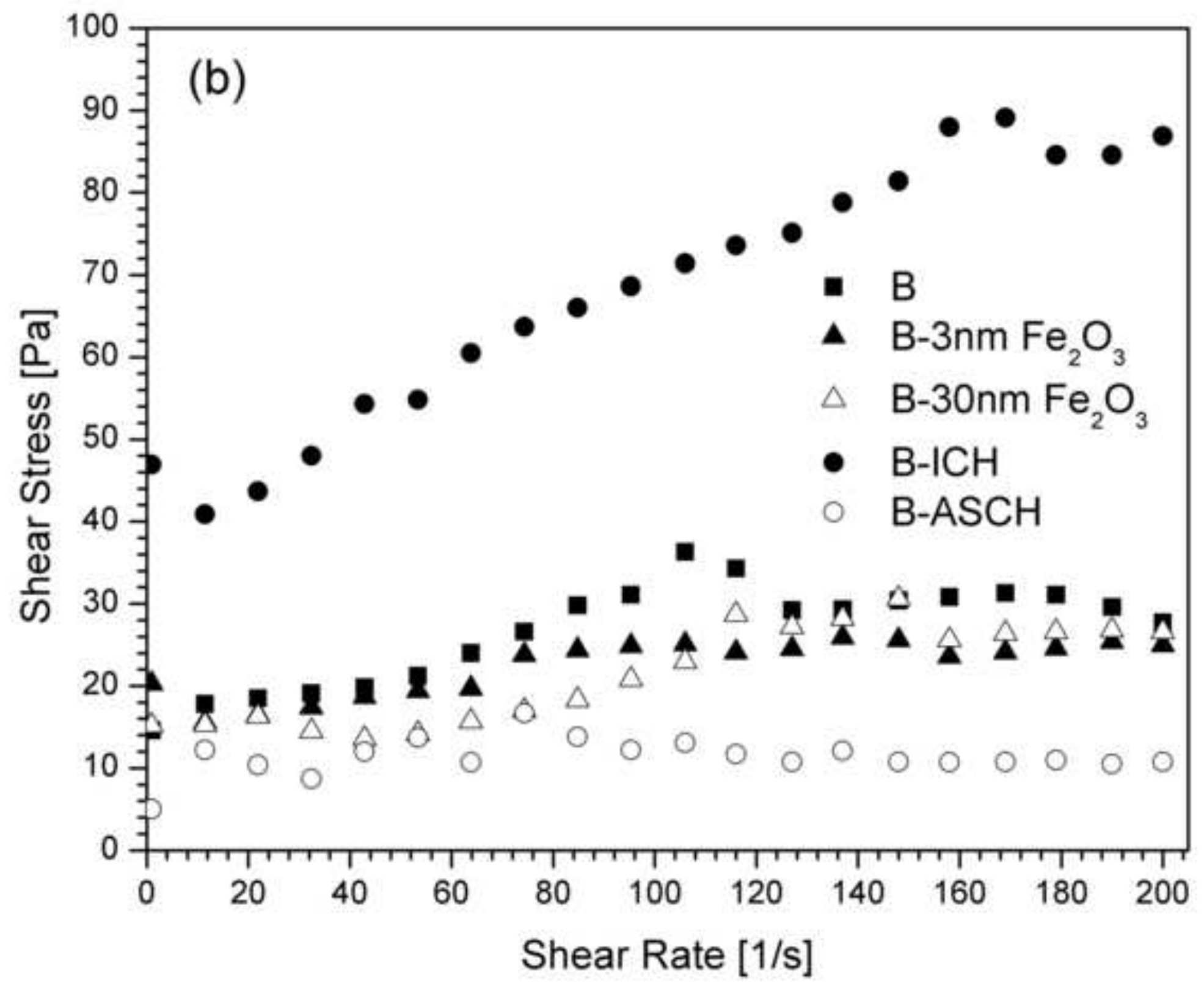




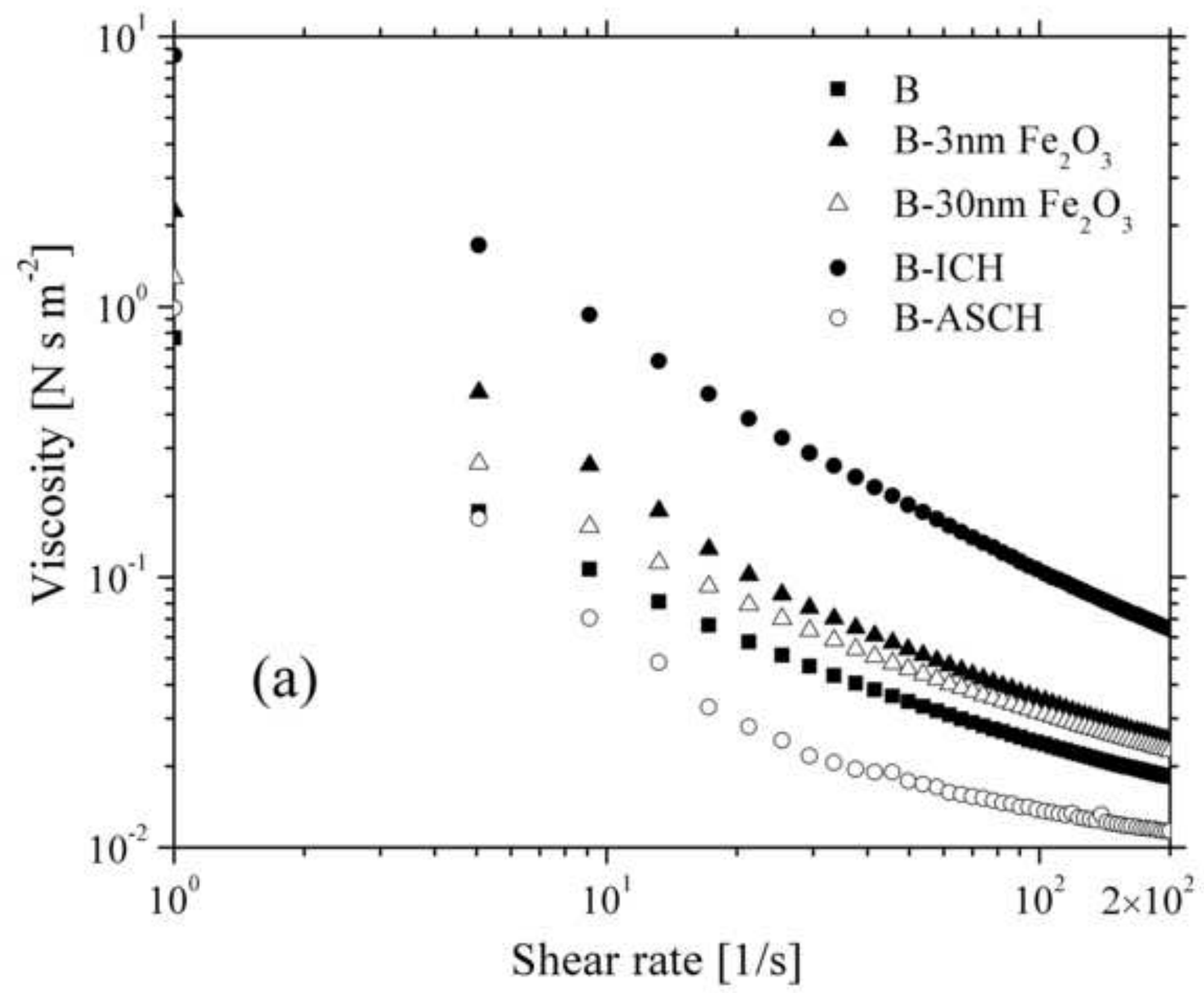




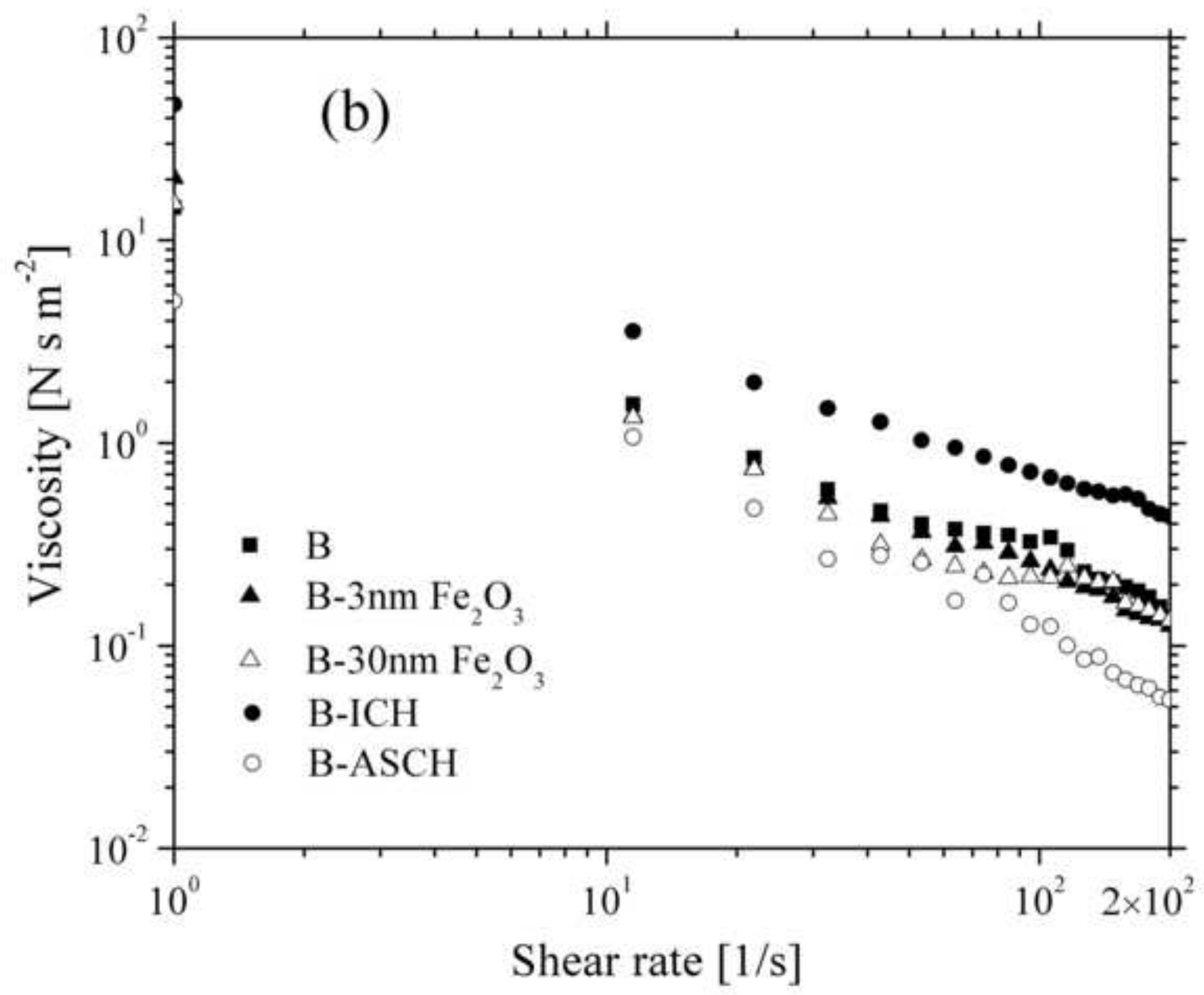




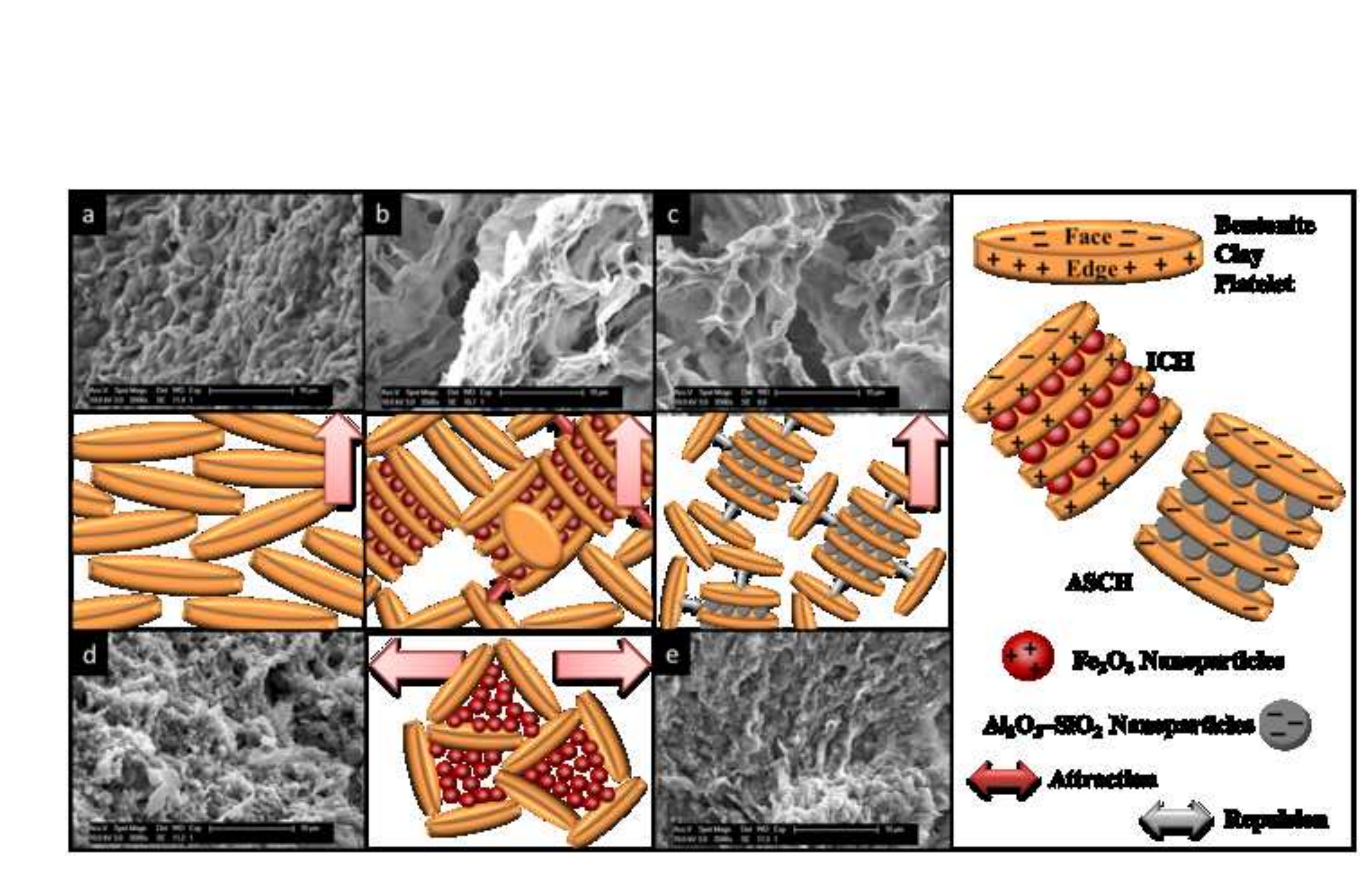




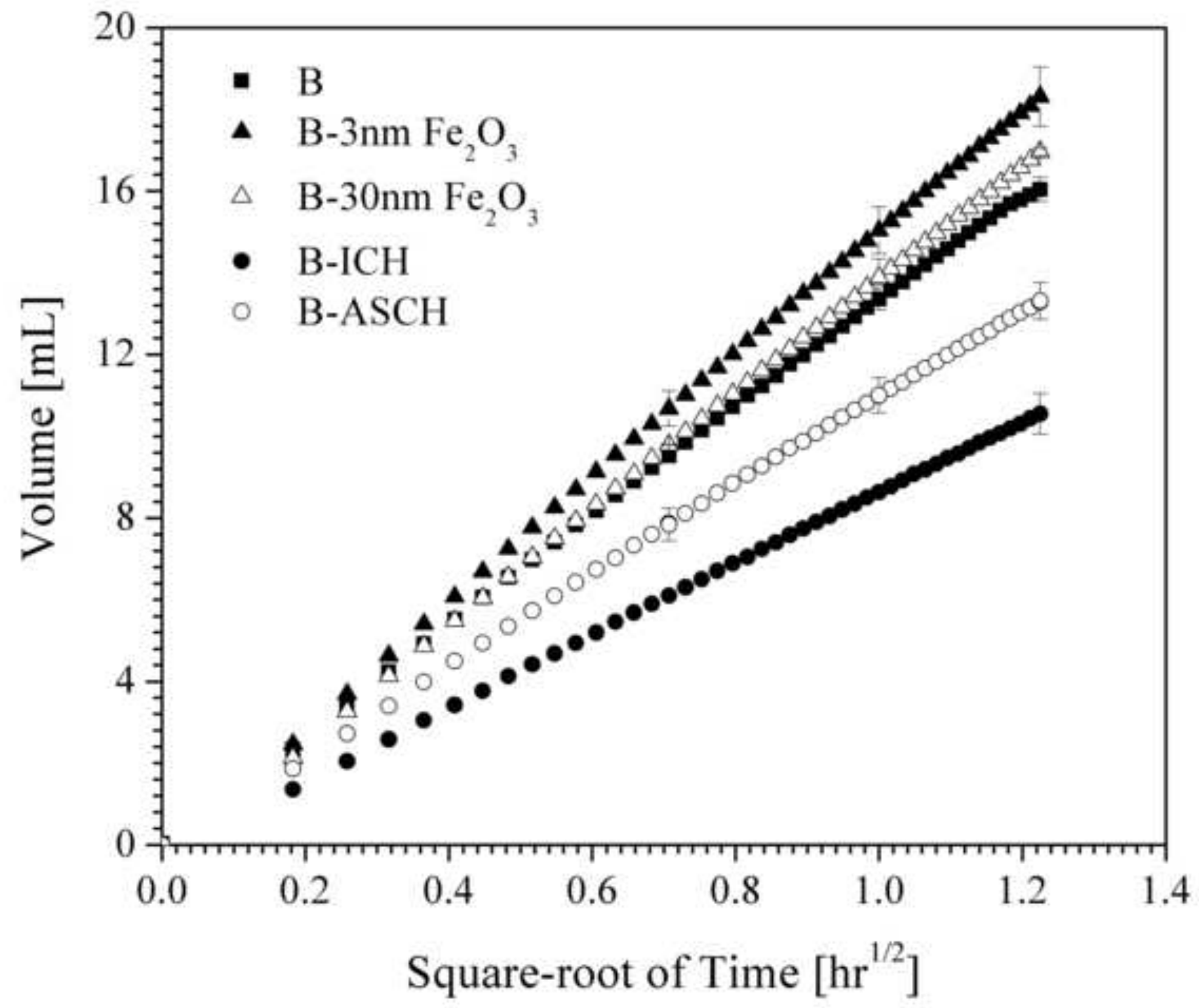




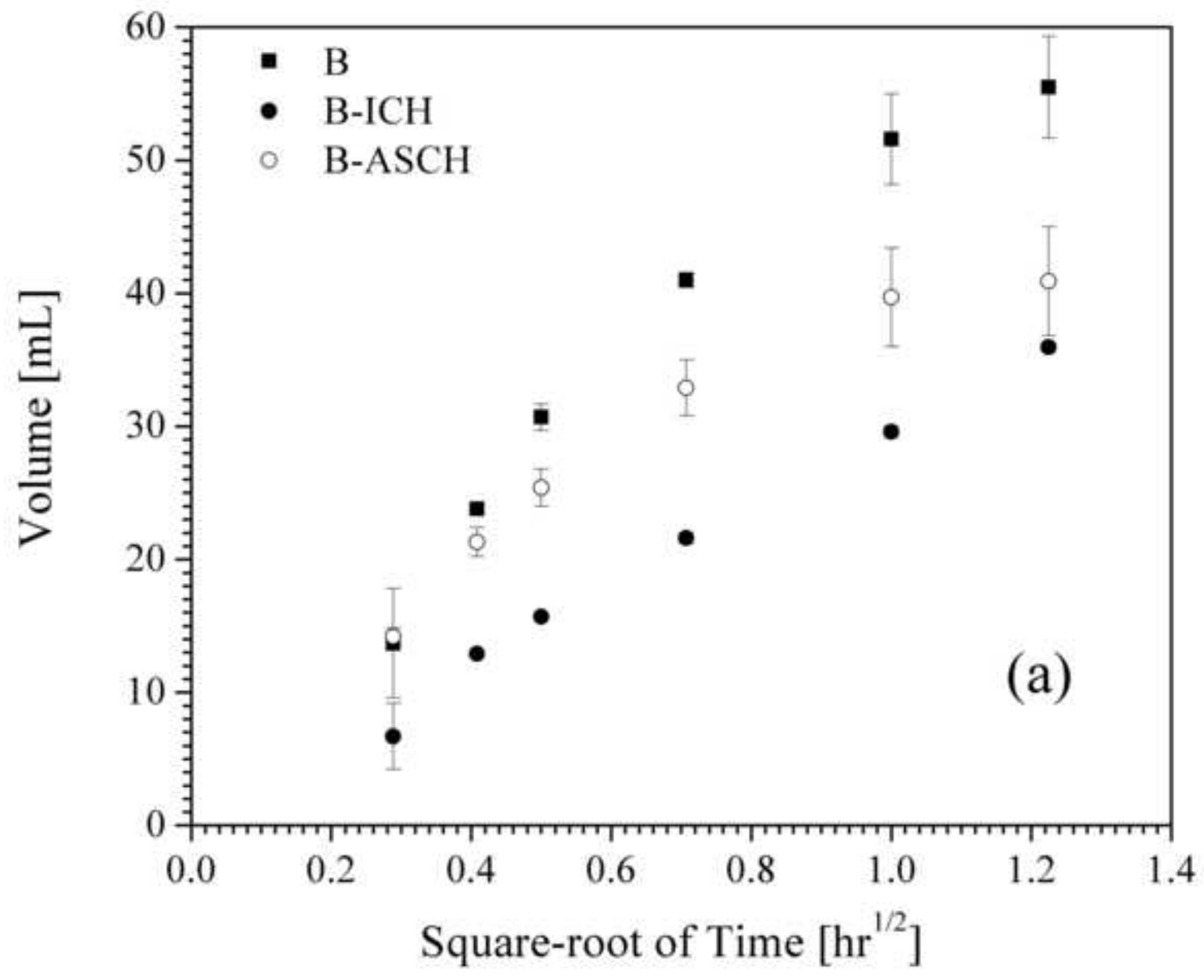




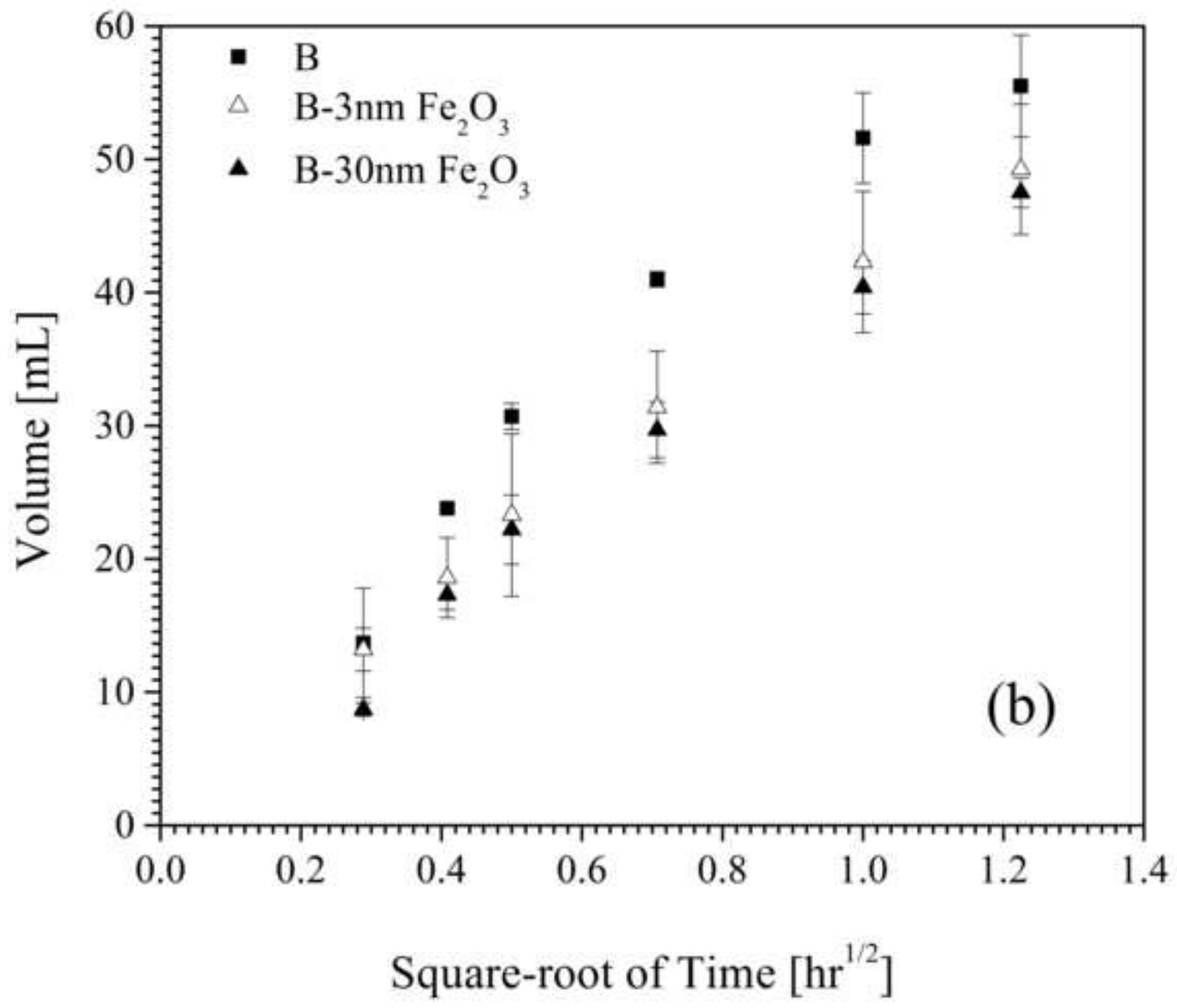

